\title{
Exposure to cosmic radiation of British Airways flying crew on ultralonghaul routes
}

\author{
M Bagshaw, D Irvine, D M Davies
}

\begin{abstract}
British Airways has carried out radiation monitoring in Concorde for more than 20 years and has used a heuristic model based on data quoted by the National Aeronautics and Space Administration (NASA) to model radiation exposure in all longhaul fleets. From these data it has been calculated that no flight deck crew would exceed the control level of $6 \mathrm{mSv} / \mathrm{y}$ currently under consideration by regulatory authorities, which is three tenths of the occupational dose limit of $20 \mathrm{mSv} / \mathrm{y}$ recommended by the International Commission on Radiological Protection (ICRP). The model suggested that less than $4 \%$ of cabin crew based in Tokyo flying only between London and Japan could reach or exceed the $6 \mathrm{mSv} / \mathrm{y}$ level, based on a predicted effective dose rate of 7 $\mu \mathrm{Sv} / \mathrm{h}$. To validate this calculation a sampling measurement programme was carried out on nine round trips flown by a Boeing 747-400 between London and Tokyo. The radiation field was measured with dosimeters used for routine personal monitoring (thermoluminescence dosimeters (TLDs) and polyallyldiglycol carbonate neutron dosimeters). The limitations of the methodology are acknowledged, but the results indicate that the effective dose rate was $6 \mu \mathrm{Sv} / \mathrm{h}$ which is consistent with the predicted effective dose rate of $7 \mu \mathrm{Sv} / \mathrm{h}$. This result, which is in accordance with other reported studies indicates that it is unlikely that any of the cabin crew based in Tokyo exceeded the 6 mSv/y level. In accordance with "as low as reasonably achievable" principles British Airways will continue to monitor flying crew routes and hours flown to ensure compliance.
\end{abstract}

(Occup Environ Med 1996;53:495-498)

Keywords: cosmic radiation; flying crew; longhaul flights

Cosmic radiation was first observed in 1912 by the Austrian physicist and balloonist, VF Hess, since when research has continued to develop knowledge and understanding of the earth's radiation field.
The earth is exposed to natural radiation from terrestrial and extra-terrestrial sources, the extra-terrestrial sources being referred to as cosmic radiation.

Galactic cosmic radiation originates from outside the solar system and produces a steady, reasonably predictable, low intensity flux of high energy charged particles, neutrons, photons, and neutrinos which are generated when the primary protons and $\alpha$ particles interact with constituents of the earth's atmosphere. The primary and secondary radiation thus produced in the atmosphere is referred to as galactic cosmic radiation. There is about an 11 year cycle in the intensity of galactic radiation reaching the earth's atmosphere, with the intensity being inversely related to solar activity. The last solar maximum was in 1991 and the next minimum during 1996/97, with an anticipated $20 \%$ difference in dose rates based on the results of measurements included in a recent review paper. ${ }^{1}$

A second source of cosmic radiation is the release of charged particles from the sun but these are of lower energy and generally contribute little to the atmospheric radiation. However, occasionally the numbers and energies of ejected solar particles become significant and this occurs during periods of solar flare. A significant solar flare occurred in February 1956 when the dose equivalent rate at $10 \mathrm{~km}$ (about $33000 \mathrm{ft}$ ) was around 10 $\mathrm{mSv} / \mathrm{h} .^{2}$ Since 1956, there have been six recorded significant solar events in which the intensity of the solar radiation rose substantially above that of galactic radiation, ${ }^{3}$ but there is no known instance of the Concorde supersonic transport aircraft (SST) emergency flightplan, which is triggered at $0.5 \mathrm{mSv} / \mathrm{h}$, being activated when the aircraft was flying during these events. ${ }^{4}$

To follow "as low as reasonably achievable" principles this would involve, subject to air traffic control approval, Concorde's immediate descent to a lower altitude.

Protection from radiation is provided by the geomagnetic field and the attenuating effect of the earth's atmosphere. Geomagnetic shielding decreases with increasing geomagnetic latitude, radiation levels over the polar regions at typical subsonic cruising altitudes of $12 \mathrm{~km}$ (about $39000 \mathrm{ft}$ ) being about twice those over the equator at the same altitudes.

The cosmic radiation dose also increases 
with altitude such that the dose equivalent at $18 \mathrm{~km}$ (about $59000 \mathrm{ft}$ ) is roughly twice that at $12 \mathrm{~km}$ (about $39000 \mathrm{ft}$ ).

\section{Radiological protection}

The International Commission on Radiological Protection (ICRP) has published recommendations ${ }^{5}$ which take account of new biological information and approaches to the setting of safety standards. It has also now recommended that exposure of crew to cosmic radiation in jet aircraft should be considered part of occupational exposure, which implies radiological surveillance of flying crew. The recommended mean principal whole body limits on effective dose are (over five years) $20 \mathrm{mSv} / \mathrm{y}$ for workers (which would include flying crew) and $1 \mathrm{mSv} / \mathrm{y}$ for the public. There is the additional recommendation that equivalent dose to the foetus should not exceed $1 \mathrm{mSv}$ during the declared term of pregnancy.

The equivalent dose in an organ or tissue is the mean absorbed dose modified by the radiation weighting factor, based on the type and quality of the external radiation field. The effective dose is the sum of organ or tissue equivalen doses each weighted by a factor which takes account of the probability of a particular effect. Quality factors are also modifying factors applied to absorbed dose to take account of the type and quality of the radiation field. They are, however, different in concept to the radiation weighting factors. The result of modifying absorbed dose with quality factors is termed dose equivalent.

Since the recent ICRP recommendations, ${ }^{5}$ the values of effective dose for neutrons are about $50 \%$ greater than the previous recommended values of the limit for the cosmic radiation fields.

In accordance with standard radiological control practice, the United Kingdom National Radiological Protection Board (NRPB) recommends that there should be a systematic assessment of the individual dose of those workers considered likely to receive an effective dose of more than $6 \mathrm{mSv} / \mathrm{y} .^{6}$

\section{Supersonic transport (SST) flights}

The Concorde SST entered service with British Airways and Air France in 1969 and was designed to fly at the unprecedented commercial operating altitude of around $18 \mathrm{~km}$ (about $59000 \mathrm{ft}$ ). Concern for potential hazards to the occupants such as exposure to cosmic radiation led to monitoring equipment for ionising radiation being installed in all Concorde aircraft. Many data have been derived from this, including more than 20 years experience of the radiological environment. ${ }^{47}$

Most of the SST routes are transatlantic between latitudes N70 degrees and N40 degrees, with additional sectors between N40 degrees and N25 degrees in the eastern United States; there are occasional charter flights in higher northern latitudes. Data from these flights indicate that the radiation exposure of Concorde flying crew is unlikely to exceed $6 \mathrm{mSv} / \mathrm{y} .{ }^{47}$

\section{Subsonic longhaul flights}

Subsonic longhaul flights (greater than six hours) normally operate at an altitude in the region of $12 \mathrm{~km}$ (about $39000 \mathrm{ft}$ ) where atmospheric shielding is predicted to give about half the cosmic radiation dose rate of that at $18 \mathrm{~km}$ (about $59000 \mathrm{ft}$ ) at a similar latitude. However, the dose of cosmic radiation at polar latitudes is about twice that at the equator at a given altitude. $\mathrm{A}$ dose rate received from a transatlantic Concorde flight, in the region of $10 \mu \mathrm{Sv} / \mathrm{h}$, can therefore be thought of as an upper limit for the worst case transpolar subsonic flight.

The introduction of the Boeing 747-400 aircraft has led to the development of ultralonghaul flights of up to 16 hours duration, some of which are trans-polar or transSiberian, where geomagnetic and atmospheric shielding are less than for routes at lower latitudes.

Other longhaul flights are trans-equatorial or east-west at near equatorial latitudes.

Two crews are normally carried on the ultralonghaul flights so that each crew works half the flying hours, but of course they take their rest on board the aircraft. They are thus exposed to cosmic radiation during both their working and non-working hours but are considered to be on duty during the whole flight, their permitted flying hours being limited accordingly. British Airways flight deck crew flying mixed longhaul and ultralonghaul flights fly up to 600 hours a year.

It should be noted that flight time is defined as being from the time the aircraft first moves under its own power until it ceases to move at the end of the flight. The result is that a person is in fact only at high altitude for a proportion of the recorded flying hours.

With the introduction of ultralonghaul flights between Japan and London flying the polar and trans-Siberian routes, British Airways has been using cabin crew based in Tokyo who fly only these ultralonghaul sectors, but may fly up to 900 hours a year.

With a heuristic model based on data quoted by the National Aeronautics and Space Administration (NASA), ${ }^{8}$ that provides a conservative estimate of dose equivalent based on proposed values of quality factors, ${ }^{9}$ which accounts for time at cruising altitude, time taken to achieve this altitude, and a stepwise function change for effect of latitude, a sample of flight deck and cabin crew was examined across all fleets to determine likely exposure. The arithmetic means of most of the annual dose equivalent rates varied between 2 and 4 $\mathrm{mSv} / \mathrm{y}$, and were directly correlated with number of hours flown. The only exception was a mean of just below $6 \mathrm{mSv} / \mathrm{y}$ for the cabin crew based in Tokyo. It was thought appropriate to study this group more closely with known schedules and flight hours to describe the likely distribution of exposure estimates.

A total of 145 cabin crew were assessed for the 12 months of 1992, during which the London-Osaka route supplemented the London-Tokyo route. Across the whole data set the calculated dose equivalent rate was 
$8 \mu \mathrm{Sv} / \mathrm{h}$. This is considered to represent a conservative upper limit for the effective dose.On the basis of this value, as many as $60 \%$ of the group would exceed $6 \mathrm{mSv} / \mathrm{y}$. The percentage exceeding $6 \mathrm{mSv} / \mathrm{y}$ would, however, reduce to less than $4 \%$ if the effective dose rate of $7 \mu \mathrm{Sv} / \mathrm{h}$ (a reduction of about $10 \%$ ) were used. In accordance with good radiological protection practice, a study was made of actual doses received to enable the predictions to be validated.

Work is ongoing to improve the understanding of the radiation field and the NRPB is working closely with other European laboratories in defining appropriate quantitative measurement procedures. None the less, it was considered that there is sufficient understanding to enable a preliminary survey to be performed.

\section{Aim \\ The aim of this study was to measure the cos- mic radiation field encountered throughout the London Heathrow-Tokyo Narita route flown by the Boeing 747-400 to give a guide to the valid- ity of the predicted radiation dose received by cabin crew based in Tokyo.}

\section{Equipment}

Galactic cosmic radiation can be measured actively or passively. Many detectors measure only one type of radiation accurately and usually for only a limited energy range, but they may show some sensitivity to other types of radiation.

An active, or direct reading, instrument displays the appropriate readings immediately or after a short delay, whereas passive, or integrating, instruments need to be evaluated in a laboratory after the flight. Active dosimetry can be based on Geiger-Muller counters ( $\gamma$ radiation), ionisation chambers ( $\gamma$ radiation), moderated boron trifluoride counters (neutrons), scintillation counters ( $\gamma$ radiation or neutrons), or tissue equivalent proportional counters (for mixed radiation fields) which can be set up to indicate both actual dose and dose equivalent.

The calibration and instrumentation are relatively complex and a suitable tissue equivalent proportional counter instrument was not readily available for use on this trial. Other forms of active instrumentation such as $\gamma$ and neutron dosimeters can be difficult to interpret because of the complexity of the radiation spectrum, including energetic charged particles.

It was considered that active dosimetry was not appropriate for this study.

Passive dosimeters have the advantage of being small, light, and robust and are readily available. Compared with active dosimeters, they are relatively much less sensitive. However, this can be overcome by increasing the exposure time.

Standard thermoluminescence dosimeters respond to $x$ and $\gamma$ radiation and also to charged particles (electrons, protons, muons, etc) and can give a good estimate of tissue dose equivalent for the non-neutron components of the cosmic radiation field at aviation altitudes. A fuller understanding of the radiation field is required to correct the results of thermoluminescence measurements from the thermoluminescence dosimeters for the difference in response efficiencies to different types of radiation and to determine the relation of tissue dose equivalent to other quantities. However, from a consideration of kerma factors and stopping power ratios for the dosimeter, detector material, and for tissue, and based on the flat depth-dose distribution in tissue for the non-neutron component, ${ }^{10}$ the measured value of tissue dose for a caesium137 photon calibration is considered to be a good estimate, within $10 \%-20 \%$ of effective dose for the non-neutron component.

The neutron component of the radiation field was measured by a polyallyldiglycol carbonate (PADC, also known as CR39) dosimeter. This responds to neutrons of all energies above about $100 \mathrm{keV}$ (and also to thermal and epithermal neutrons) and its response characteristics are known up to $70 \mathrm{MeV}$. The PADC dosimeter responds also to high energy protons. On the assumption of an isotropic neutron field and for representative neutron spectra, the neutron fluence calculated from the response of the track detectors may be converted to an estimated value of effective dose. Because of the assumptions made and incomplete knowledge of both detector response characteristics and the radiation field, there is a correspondingly greater uncertainty, estimated at around $30 \%$, in the value of effective dose for the neutron component.

Notwithstanding the limitations, based on advice from NRPB, it was considered that a combination of thermoluminescence dosemeters and PADC dosimeters was appropriate for use in this validation study.

\section{Method}

Packs were prepared and supplied by the NRPB consisting of sealed plastic bags containing two PADC neutron and two thermoluminescence dosimeters suitable for installation in a British Airways Boeing 747-400 aircraft.

Suitably labelled packs were installed on vertical surfaces on the flight deck, in the wardrobes of the upper deck, the first class area, the club (business) area, the world traveller (economy) area, and in the cabin crew rest area. They were secured by tape, situated away from strong heat sources, and left undisturbed in situ for the duration of the study.

Also a pack was put on the ground at London Heathrow Airport and another at Tokyo Narita Airport, remaining at these sites for the duration of the measurement programme.

Nine return flights were made between London and Tokyo, departing between 11 May 1993 and 2 June 1993.

The dosimeters from the aircraft and from the ground stations were returned to the NRPB on 8 June 1993 and processing was completed within three days.

\section{Results}

Eighteen non-stop sectors were recorded between London Heathrow and Tokyo Narita 
airports. The mean sector flying time was 11.5 hours, with 10 hours spent above an altitude of $10 \mathrm{~km}$ (about $33000 \mathrm{ft}$ ).

The latitudes varied between N39 degrees and N66 degrees, with a mean time above N50 degrees on each sector of 10 hours.

Ground level background radiation was measured at Heathrow and Narita airports as 0.07 $\mu \mathrm{Sv} / \mathrm{h}$

Analysis of the thermoluminescence dosimeters gave a value, rounded up, for inflight $x, \gamma$, and charged particle components of $3 \mu \mathrm{Sv} / \mathrm{h}$.

The inflight neutron component measured by the PADC dosimeters also gave a rounded up value of $3 \mu \mathrm{Sv} / \mathrm{h}$.

The mean effective dose rate was calculated to be around $6 \mu \mathrm{Sv} / \mathrm{h}$ (with an uncertainty of about $20 \%$ ) giving an effective dose for the return London-Tokyo flight in the region of $120 \mu$ Sv.

No significant variation in dose rate between the dosimeter locations on the aircraft was found.

\section{Discussion}

Interpretation of these data requires some caution as further work is necessary to take better account of the characteristics of the radiation field and the most appropriate quantity to be measured. This is being considered by the NRPB and other European laboratories. None the less, this study has produced results which are consistent with the values of exposure to radiation predicted by existing theoretical models. There is also good agreement with similar investigations performed in the United States, ${ }^{11}$ Germany, ${ }^{12}{ }^{13}$ Sweden, ${ }^{14}$ France, ${ }^{15}$ Czechoslovakia, ${ }^{16}$ and Japan, ${ }^{17} 18$ and reviewed by the European Radiation Dosimetry Group (EURODOS). ${ }^{1}$

The heuristic model with a dose equivalent level of $8 \mu \mathrm{Sv} / \mathrm{h}$ is overly conservative in implying that as many as $60 \%$ of the cabin crew based in Tokyo could exceed $6 \mathrm{mSv} / \mathrm{y}$ if the effective dose were the same. For the experimentally determined effective dose rate of $6 \mu \mathrm{Sv} / \mathrm{h}$ none of this potentially high risk group would exceed the $6 \mathrm{mSv} / \mathrm{y}$ level where roster restrictions would have to be contemplated.

With due account taken of the "as low as reasonably achievable" principles we can thus be satisfied that the existing monitoring procedure, based on duration, altitude, and latitude of flight using our heuristic model, is a good approximation for immediate practical purposes, but requires further refinement and confirmation against measured data. We also have confidence that with existing flight schedules it is impossible for any flight deck crew member even to approach the annual dose limit given in the new ICRP recommendations.

In the case of those few cabin crew based in Tokyo who may approach the occupational control limit, roster restrictions could be contemplated.

\section{Conclusion}

The direct flight between London Heathrow and Tokyo Narita represents the worst case for cosmic radiation exposure for British Airways longhaul flying crew, particularly the cabin crew based in Narita who fly this route regularly. Prediction of the radiation exposure of this group showed that $60 \%$ had yearly dose rates in the order of $6 \mathrm{mSv}$ based on an upper limit effective dose rate of $8 \mu \mathrm{Sv} / \mathrm{h}$, but less than $4 \%$ for an estimated effective rate of $7 \mu \mathrm{Sv} / \mathrm{h}$. Although well within the dose limit of 20 $\mathrm{mSv} / \mathrm{y}$, a suggested control limit of exposure of 6 $\mathrm{mSv} / \mathrm{y}$ above which individual assessment of dose and dose recording would be required, may be set, and this would conform with existing British Airways practice.

The effective dose rate of $6 \mu \mathrm{Sv} / \mathrm{h}$ estimated from measurements is, however, consistent with the conservatively calculated value of 7 $\mu \mathrm{Sv} / \mathrm{h}$, and although subject to a degree of uncertainty, indicates that it is unlikely that any of the cabin crew based in Tokyo, who represent the group most at risk, will exceed 6 $\mathrm{mSv} / \mathrm{y}$.

No British Airways flight deck crew members approach the ICRP recommended control level or dose limit.

We acknowledge the advice and technical assistance given by Dr D T Bartlett of the National Radiological Protection Board, Chilton, Didcot, Oxfordshire.

1 Bartlett DT, McAulay IR, Schrewe UJ, Schnuer K, Menze HG, Bottollier-Depois J-F, et al. Dosimetry for occupational exposure to cosmic radiation, presented at the 8th sym posium on neutron dosimetry, Paris, 13-17 November 1995

2 Foelsche $T$. Radiation safety in high altitude air traffic fournal of Aircraft 1977;14:1226-33

3 Friedberg W, Snyder L, Faulkner DN. Radiation exposure of members ii. Washington: Dep Transport, 1992. (Final report DOT/FAA/AM-92/2.)

4 Davies DM. Cosmic radiation in Concorde operations and the impact of new ICRP recommendations on commercial aviation. Radiation Protection Dosimetry 1993;48:121-4.

5 International Commission on Radiological Protection publication 60. Annals of the ICRP 1991;21:1-3.

6 Document of the National Radiological Protection Board. Chilton, Oxford: NRPB 1993,4.

7 Preston FS. Eight years of Concorde operations: medical aspects. $\mathcal{F} R$ Soc Med 1985;78:193.

8 Transport methods and interactions for space radiations. Springfield, VA: NASA Technical Information Service, 1991. (NASA Ref Publ 1257, December 1991.)

9 The quality factor in radiation protection. International Commission on Radiation Units and Measurements Repor No 40, 1986. Bethesda, MD: ICRU, 1986.

10 O'Brien K, Friedburg W. Atmospheric cosmic rays at aircraft altitudes. Environment International 1994;20: 645-63.

11 Friedberg W, Faulkner DN, Snyder L, Darden EB Jr, O'Brien K. Galactic cosmic radiation exposure and assoO'Brien K. Galactic cosmic radiation exposure and associated health risks for air carrier crew
Space Environ Med 1989;60:1104-8.

12 Regulla D, David J. Radiation measurements in civil aviation. Final report GSF/BGIDLH research project. Germany: Institut fur Strahlenschutz, 1993.

13 Schuhmacher H, Schrewe UJ. Dose equivalent measurements on board civil aircraft. Braunschweig, Germany: 1993. (Report PTB-Bericht N-13.)

14 Lindborg L, Karlberg J, Elfhag T. Legislation and dose equivalents aboard domestic flights in Sweden. Stockholm: Swedish Radiation Protection Institute, 1991. (SSI Report 91-12.)

15 Nguyen VD, Lebaron-Jacobs L, Bouisset P, Kerlau G, Itie $C$, Montagne $C$, et al. Real time determination of the , Mulity fortor $\mathrm{C}$, et al. Real time determination of the quality factor and dose equivalent of cosmic radiation aboard French airliners. In: Proceedings of the 40th International Congress of Aviation and Space Medicine Tokyo: Institute of Protection and Nuclear Safety 1992.

16 Spurny F, Obraz O, Pernicka F, Votockova I, Turek K Dosimetry on board subsonic aircraft, CSA flight routes, data and their new interpretation. In: Proceedings of the 24th Symposium on Radiation Protection Physics. Gaussig Germany: 1992

17 Sekiya T, Kaji M, Ando H, Miyazaki H, Asukata I, Hamaguchi $\mathrm{N}$, et al. Galactic cosmic gamma ray exposure on subsonic aircraft. In: Proceedings of the 41st International Congress of Aviation and Space Medicine. Hamburg, Germany: Congress Centrum, 1993.

18 Kaji M, Fujitaka K, Sekiya T, Asukata I, Ohkoshi H Miyazaki $\mathrm{H}$, et al. In-situ measurements of cosmic radiation dose equivalent on board aeroplanes to/from Japan 2nd report. Aviat Space Environ Med 1995;66:487. 